\title{
Compassion fatigue: A Study of critical care nurses in Turkey
}

\author{
Yurdanur Dikmen ${ }^{1}$ \\ Yasemin Aydin ${ }^{2}$ \\ Pınar Tabakoğlu ${ }^{3}$
}

\begin{abstract}
This study was conducted to determine the level of compassion fatigue which experienced by nurses who work in intensive care units and factors that affecting it.

In a cross sectional design, critical nurses were surveyed by using questionnaire and compassion fatigue (CF) subscale of the Professional Quality of Life Scale (ProQOL R-IV) to measure levels of compassion fatigueat a large National Education and Research Hospital located in north west of Turkey. A total of 69 critical care nurses participated in the study, for a response rate of $78 \%$.A series of cross tab analyses examined the relationship between nurses demographics and compassion fatigue (CF) subscale. To analyze the data further, participants were recategorized into 2 groups for CF scores: (1) higher than 17: high risk and (2) lower than 17: low risk.

Findings show that critical care nurses were at high risk (52.7\%) and low risk (47.3\%) for CF. Nurses informed significant differences in compassion fatigue on the basis of age, years of critical care experience, working hours (weekly).
\end{abstract}

Keywords: Compassion; Compassion Fatigue; Nursing Care; Critical Care Nurses.

\section{Introduction}

Compassion fatigue is defined as the physical, emotional, social and spiritual exhaustion which causing widespread reduction of empathizing, caregiving and energy in caregivers[1]. Compassion fatigue is a natural result of working with individuals experiencing trauma or stressful events.Therefore, nurses are the professional group who experiencing compassion fatigue intensively due to the long exposure to the traumas experienced by the patients, showing mercy to their traumas, suffering and pains and empathizing with them. Despite compassion fatigue is studied in all areas of nursing, the majority of studies focus on nurses working in intensive care, oncology, pediatrics, palliative care and emergency services [2,3,4,5,6,7,8,9,10,11]. In conducted studies, it is stated that the emergency and intensive care nurses who consituting the sample group experienced compassion fatigue in moderate level and one-third of them were in a high risk category in terms of living compassion fatigue $[6,12,13,14]$. However, in the literature, it was found that there knowledge gap and different opinions in prevention of prevalence of compassion fatigue in intensive care nurses or implementing effective interventions to treat it[15].

\footnotetext{
1 Associate Professor, Ph.D., Sakarya University, Health High School, Department of Nursing, Sakarya, Turkey, nurdem35@gmail.com

2 Research Assistant, Ph.D., Sakarya University, Health High School, Department of Midwifery, Sakarya, Turkey, yaseminaydin@sakarya.edu.tr

${ }^{3}$ M.Sc., Sakarya University, Education and Research Hospital, Sakarya, Turkey, kara.pnar@yahoo.com.tr
} 
The purpose of the present study was to examine the symptoms of CF and predicting these symptoms in Turkish critical care nurses. Nursing is one of the stressful jobs and is related to helping patients. So, research about the prevalence of the CF and variables related to health of nurses plays an important role in improving the mental and physical health of nurses in Turkey. Information about the relationship among CF and its effect can help researchers, psychologists, counselors and organizations to provide the social support for improving the health of nurses.

\section{Study Design}

This descriptive, cross-sectional study was conducted to assess participants' level of compassion fatigue by using compasion fatigue (CF) subscale of ProQOL R-IV.This descriptive analysis of a quality-improvement evaluation of critical care nurses was conducted at a large National Education and Research Hospital located in northwest of Turkey. This facility is a national education and research hospital with 935 licensed beds. It offers nearly 120 specialty areas to patients and also serves as the region's level I health center.

\section{Sample}

This study was conducted between December 2015 and February 2016. A total of 88 nurses work in the intensive care unit at the hospital where the study was conducted. The sample of the study consisted by total of 69 nurses who were working at adult intensive care units and volunteer to participate in the study.

\section{Data Collection}

In the collection of research data, demographic questionnaire which includes sociodemographic features and CF subscale of Professional quality of life (ProQOLR-IV) were used. Data was collected by researchers with the method of face to face interview.

Demographic Questionnaire:The demographic information sheet was used to obtain information regarding age, gender, critical careexperience, marital status, education level, and weekly work hours.

The Professional quality of life (ProQOL R-IV):This scale was developed by Figley (1996) and revised by Stamm (2005), [16,17]. Yesilet all. (2010) determined that the ProQOL has high reliability and validity and it can be used to measure quality of life in Turkish society[18].The ProQOL includes three 10-item subscales: CS, BO, and CF. TheProQOL involves selecting response choices on a 0 (never) to 5 (very often) Likert scale. Higher scores represent greater severity of CS, BO, and CF. CF scores which may indicate danger are greater than 17 . CF subscale was used in the current study and the alpha reliabilities for CF was 0.81. For this research, total Cronbach alpha reliability coefficient of the scale was found to be 0.81 .

\section{Data Analysis}

Collected data were analyzed with the IBM SPSS Software version 16. Before analysis, the data were examined for outlying and missing data. Descriptive statistics were used to analyze demographic data, including age, gender, number of years working in critical care unit, weekly work hours, and education background. A series of cross tabs were calculated to show the relationship between demographics and total scores on CF subscale, using Pearson Chi square analysis. Statistical significance was taken as 0.05 .

\section{Ethical Considerations}

Firstly, all nurses were offered general information about the study before participation. Written Permission has been taken from the hospital's research committee in order to conduct this research. 


\section{RESULTS}

A total of 69 critical care nurses participated in the study, for a response rate of $78 \%$. Participants' age ranged from 20 to 50 years. About $58 \%$ of the participants had bachelor's and master's degrees, and another $21.7 \%$ had associate's degrees. For years of experience as critical care nurse, $23.2 \%$ had 0 to 1 years of experience, $24.6 \%$ had 2 to 5 years of experience, $27.5 \%$ had 6 to 10 years of experience, and $24.6 \%$ had 11 year and higher years of experience. More than half of respondents worked more than 40 hours a week.

Figure 1 shows that $52.7 \%$ and $47.3 \%$ of critical care nurses were at high risk and low risk for CF, respectively.

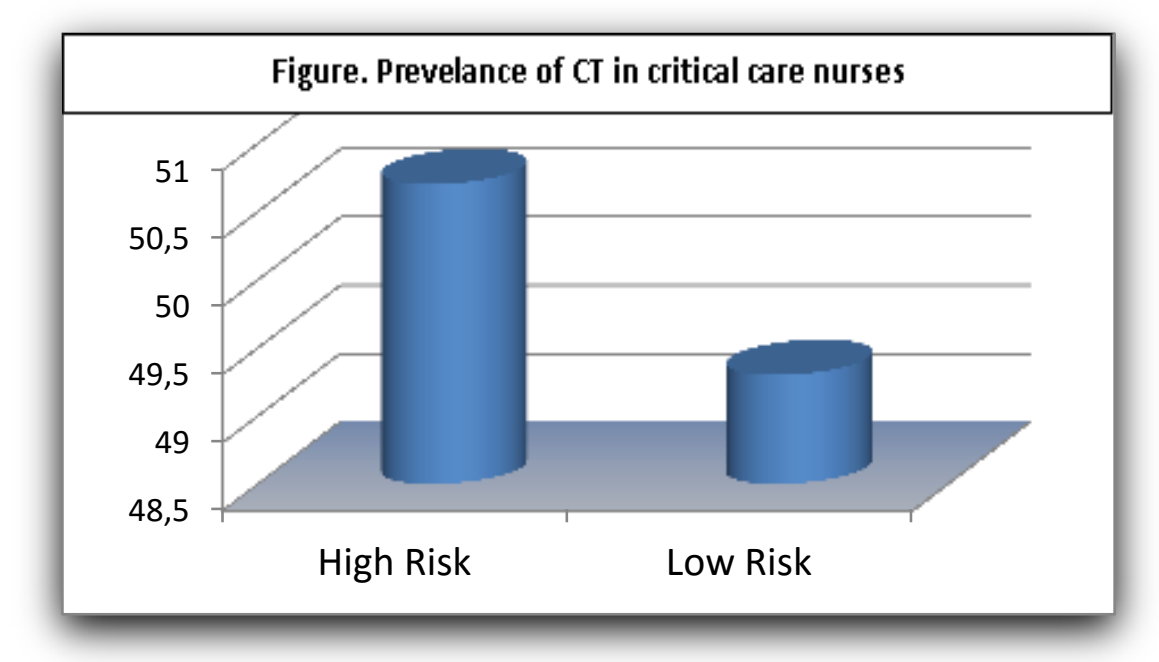

To analyze the data further, participants were recategorized into 2 groups for CF scores: (1) higher than 17: high risk and (2) lower than 17: low risk. Afterward, were performed Pearson Chi square analysis for demographics data.These were compared with the study variables, including the participants' age, gender, years of critical care experience, working hours (weekly) and level of education. Findings were statistically significant for the relationship between CF scores and age groups of nurses $(\mathrm{p}=0.040)$. Younger nurses $(20-35$ years $)$ had the highest percentage of high risk CF scores. Although $54 \%$ of female nurses scored at high risk for CF compared to $25 \%$ for male nurses, the difference was not statistically significant $(\mathrm{p}=0.110)$. A significant relationship was found between years of critical careexperience and CF scores. The nurses with 0-1 years of critical care experience had the highest percentage of high risk compassion fatigue scores, followed by those with 2-5 years of experience $(p=0.011)$. Besides, findings were statistically significant for the relationship between $\mathrm{CF}$ scores and weeekly working hours $(\mathrm{p}=0.024)$. Higher than 40 hours per week working on nursing units had the highest percentage of high risk CF scores (Table 1). 
Dikmen, Y., Aydın, Y., \& Tabakoğlu, P. (2016). Compassion fatigue: A Study of critical care nurses in Turkey. Journal of Human Sciences, 13(2), 2879-2884. doi:10.14687/jhs.v13i2.3752

Table 1.Results of Cross Tab Analysis and Demographics of CF subscale of ProQOL RIV*

\begin{tabular}{|c|c|c|c|c|c|}
\hline \multirow{3}{*}{ VARIABLE } & \multicolumn{4}{|c|}{ COMPASSION FATIGUE } & \multirow[b]{3}{*}{$\mathrm{P}$} \\
\hline & \multicolumn{2}{|c|}{ HIGH RISK } & \multicolumn{2}{|c|}{ LOW RISK } & \\
\hline & $\mathrm{n}$ & $\%$ & $\mathrm{n}$ & $\%$ & \\
\hline \multicolumn{6}{|l|}{ Gender } \\
\hline Female & 31 & 54 & 26 & 46 & \multirow[t]{2}{*}{0.110} \\
\hline Male & 3 & 25 & 9 & 75 & \\
\hline \multicolumn{6}{|l|}{ Age groups of nurses } \\
\hline $20-35$ & 22 & 85 & 5 & 15 & \multirow[t]{2}{*}{0.040} \\
\hline $36-50$ & 12 & 24 & 40 & 86 & \\
\hline \multicolumn{6}{|l|}{ Education level ofnurses } \\
\hline High school & 8 & 71 & 6 & 29 & \multirow[t]{3}{*}{0.121} \\
\hline Associate's degrees & 10 & 66 & 5 & 34 & \\
\hline Bachelor's and Master's degrees & 18 & 35 & 22 & 65 & \\
\hline \multicolumn{6}{|l|}{ Years of critical careexperience } \\
\hline $0-1$ year & 10 & 62 & 6 & 38 & \multirow[t]{4}{*}{0.011} \\
\hline $2-5$ year & 10 & 42 & 7 & 58 & \\
\hline $6-10$ year & 9 & 48 & 10 & 52 & \\
\hline 11 yearand higher & 6 & 35 & 11 & 65 & \\
\hline \multicolumn{6}{|l|}{ Work hours** } \\
\hline 40 hours per week & 15 & 57 & 11 & 42 & \multirow[t]{2}{*}{0.024} \\
\hline Higher than 40 hours per week & 36 & 85 & 10 & 15 & \\
\hline
\end{tabular}

*ProQOL R-IV-Professional Quality of Life (fourth revision),

**Working hours is 40 hours per week in this hospital.

The other demographic variables were not significantly related to the CF scores, including gender and education level. However, the results of high risk for compassion fatigue were interesting in regard to nurses' education level. Nurses with aassociate's degrees had the highest percentage of high risk scores for compassion fatigue.

\section{Discussion}

As a result of the study, it was seen that more than half of intensive care nurses were found to be at risk for compassion fatigue. Besides, the most important factors affecting the compassion fatigue were found as age, much working hours and years of experience of working in intensive care. Burtson and Stichler who carrying out their studies in the field of nursing reported that compassion fatigue affects mostly young nurses and who had less nursing experience.Yoders (2010) stated that in his compassion fatigue study in nurses who had giving care in home and hospital, the less experienced nurses (less than 10 years) had greater compassion fatigue than moderate experienced (10-19) nurses [12]. These results are consistent with the results of our study. In this study, the education level of nurses does not affect the risk of compassion fatigue. However, nurses with associate degree had higher risk of compassion fatigue. Sacco et al (2015) stated that in their study which conducted with intensive care nurses; the compassion fatigue level of nurses who were more than 50, unmarried and had postgraduate is higher, Kim (2013) also in his study stated that there was a significant relationship between levels of education and compassion fatigue $[19,20]$. The nature of intensive care may increase the tension between the idealistic expectations of person and pratic applications. Nurses with higher levels of education are important resources of intensive care training programs. Therefore, managers should be able to understand 
this group's requirements better in terms of compassion fatigue and exhaustion. Although the findings do not support the causal relationship, these valuable findings can be basis for future research.

\section{Limit}

In the study, several limitations were identified. Survey of compassion fatigue response rate was $78 \%$. In addition, in order to generalize the study the variety of sample was little. Most of the participants were young (age range 20-35) and women. Another constraint was the measuring tool ProQOL5 was measuring the level of compassion fatigue only at a single point. Due to the nature of compassion fatigue had sudden beginning, the survey results performed on different days may lead to differences in the study. Our last limitation that was the study was carried out in only one hospital's intensive care unit.

\section{Conclusions and Recommendations}

Compassion fatigue on nursing care issue should be brought up especially in Turkey. Also, we should give due importance to it, and programs for avoiding and treatment of compassion fatigue should be created. In this essay, results of scientific researches about compassion fatigue and definition, effects and importance of it on nursing care has been discussed in order to increase awareness about compassion fatigue and its effects which is experienced by nurses. Additionally, when it is considered that a safe and qualified working environment affects the quality of the care the nurses provide to patients, it becomes clear that nurses should be supported against the risk of compassion fatigue and that coping strategies for this situation being taught to nurses will reflect in their life and work quality positively. Future studies involving large numbers of respondents from many hospitals, exploring situations that trigger compassion fatigue and the implementation of qualitative studies investigating available quantitative studies in depth, could contribute to enhancing the knowledge about patient care.

\section{References}

1. Figley CR. (2002). Compassion Fatigue: Psychotherapists' Chronic Lack of Self Care. J Clin Psychol. 58:1433-1441.

2. Joinson C. (1992). Coping with compassion fatigue. Nursing. 22(4): 116-121.

3. Maytum J, Heiman M, Garwick A. (2004). Compassion fatigue and burnout in nurses who work with children with chronic conditions and their families. Journal of Pediatric Health Care. 2004; 18:171-179.

4. Abendroth, M., \& Flannery, J. (2006). Predicting the risk of compassion fatigue: A study of hospice nurses. Journal of Hospice and Palliative Medicine, 8(6), 346-356.

5. Sabo B.(2008).Adverse psychosocial consequences: Compassion fatigue, burnout and vicarious traumatization: Are nurses who provide palliative and hematological cancer care vulnerable? Indian Journal of Palliative Care. 14(1): 23-29.

6. Hooper C, Craig J, Janvrin D, Wetsel M, Reimels E, Anderson G, Clemson SC. (2010). Compassion satisfaction, burnout, and compassion fatigue among emergency nurses compared with nurses in other selected inpatient specialties. Journal of Emergency Nursing. 36(5): 420-427.

7. Slocum-Gori, S., Hemsworth, D., Chan, W., Carson, A., \& Kazanjian, A. (2011). Understanding compassion satisfaction, compassion fatigue and burnout: A survey of the hospice palliative care workforce. Palliative Medicine, 27(2), 172-178.

8. WenzelJ, Shaha M., Klimmek R, Krumm S. (2011). Working through grief and loss: Oncology nurses' perspectives on professional bereavement. Oncology Nursing Forum. 38(4), E272-E282. 
9. Fetter K. (2012). One inpatient oncology unit's interventions for recognizing and combatting compassion fatigue. Clinical Journal of Oncology Nursing. 16(6), 559-561.

10. Melvin C. (2013). Professional compassion fatigue: What is the true cost of nurses caring for the International Journal of Palliative Nursing. 18(12): 606-611

11. Potter P, Deshields T, Divanbeigi J, Berger J, Cipriano D, Norris L, Olsen S. (2010). Compassion fatigue and burnout: Prevalence among oncology nurses. Clinical Journal of Oncology Nursing. 14(5), 56.

12. YoderE. (2010). Compassion fatigue in nurses. Applied Nursing Research. 23: 191-197.

13. Gök G. A. (2015). MerhametEtmeninDayanılmazAğırlığı: HemşirelerdeMerhametYorgunluğu. Süleyman Demirel Üniversitesi İktisadi ve İdari Bilimler Fakültesi Dergisi. 20(2):299-313.

14. Hegney D G, Craigie M, Hemsworth D, et al.(2014). Compassion Satisfaction, Compassion Fatigue, Anxiety, Depression and Stress in Registered Nurses in Australia: Study 1 Results. Journal of Nursing Management. 22(4):506-518.

15. Dikmen Y, Aydın Y. (2016). Hemşirelerde Merhamet Yorgunluğu: Ne? Nasıl? Ne Yapmalı?. J hum rhythm. 1(1):13-21.

16. Figley C.(1995). Compassion Fatigue: Coping With Secondary Traumatic Stress Disorder in Those Who Treat the Traumatized. New York.

17. Stamm BH. (2005). The ProQOL manual. The professional quality of life scale: Compassion satisfaction, burnout \& compassion fatigue/secondary trauma scales. Retrieved from http:// www.compassionfatigue.org/pages/ProQOLManualOct05.pdf.

18. Yeşil A, Ergün Ü, Amasyalı C, Er F ve ark. (2010). ÇalışanlarİçinYaşamKalitesiÖlçeğiTürkçeUyarlamasıGeçerlikVeGüvenilirlikÇalışması. NöropsikiyatriArşivi. 47:111-117.

19. Sacco TL, Ciurzynski SM, Harvey ME, Ingersoll GL. (2015). Compassion Satisfaction and Compassion Fatigue Among Critical Care Nurses. CriticalCareNurse. 35(4): 32-44.

20. Kim S. (2013). Compassion fatigue in Liver and Kidney Transplant Nurse Coordinators: A Descriptive Research Study. Progress in Transplantation. 23(4):329-335. 